\title{
Determination of the duration of deburring at vibro-abrasive treatment of parts in organic media
}

\author{
Yelena Kolganova ${ }^{1,{ }^{*}, \text { Ivan } \text { Vyalikov }^{1} \text {, Anna Azarova }}{ }^{1}$, Roman Mishchenko ${ }^{1}$ and Georgiy \\ Sanamyan $^{2}$ \\ ${ }^{1}$ Don State Technical University, 344000 Rostov-on-Don, Russian Federation \\ ${ }^{2}$ Rostov State Transport University, 344038 Rostov-on-Don, Russian Federation
}

\begin{abstract}
Basing on the radio-electronic equipment parts design and technological features analysis and granular media vibration treatment process main technological principles, a process model has been developed providing surfaces parts effective finishing and cleaning treatment by means of organic origin working media. Complex-profile devices parts bone organic media vibration treatment experimental studies have been carried out.
\end{abstract}

\section{Introduction}

Radio-electronic equipment (REE) reliability and quality ensuring problems growing importance recently observed is largely due to the modern devices design and functionality constant complication coupled with their simultaneous material consumption and overall dimensions reduction.

Considering the volumetric vibration treatment (VVT), peculiar of its performance and versatility $[1,2,3]$, as one of the most promising and effective ways to solve devices parts finishing problem, the fact of its insufficient practical application in the REE parts finishing technology should be recognized. At present, the main limiting reasons are constituted by the lack of science-based finishing and cleaning operations designing methods, which would provide an optimal processing technological media type and granulometric parameters choice and, as a result, the required surface quality corresponding to operating conditions, taking into account the parts design features $[4,5,6]$.

\section{Processing media grain-size characteristics choice principles in the REE details VVT process}

The problem of choosing the optimal treatment environment for performing REE parts VVT, which requires, first of all, burrs removing and preparing surfaces for subsequent coating $[7,8,9]$, should be attributed as a multi-factor one and rather difficult to solve. As

* Corresponding author: elenkolg@list.ru 
proved by the device parts design and technological features analysis, it is most acceptable to use for their VVT the treatment media characterized by a sufficiently high density and a low pellet weight, allowing to treat the conjugated workpiece surfaces with limited access for the medium working bodies, having a uniform granule structure and high wear resistance.

Approaching the VVT processing medium choice from these positions, according to the research results $[10,11,12]$, all the above-mentioned requirements will be met by working environments consisting of crushed walnut shell granules and fruit trees bones.

When crushing the stiffened bones shells, random shape granules are formed with the presence of wedge-shaped edges along the perimeter (Fig. 1), which allows us to consider such granules as a tool cutting the surface to be treated and having access to the conjugated and hard-to-reach workpiece surfaces[13, 14]. That is why bone organic media can be proposed for finishing REE parts with small-sized slots and holes.

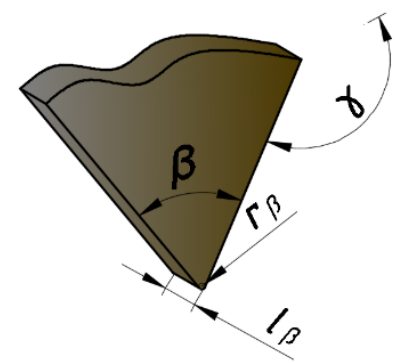

Fig. 1. Granule macrogeometric parameters. $\beta$ is the angle formed by the edge wedge; $r_{\beta}$ is the radius at the edge vertex; $1_{\beta}$ is the single edge length; $\gamma$ is the angle determining the neighboring edges position.

\section{Deburring process modeling when performing VVT with s bone media}

When evaluating the organic origin pellets treatment efficiency, it can be assumed that when the pellet comes into contact with the workpiece surface, metal removal occurs by scratching, stipulating the micro-cutting process by the wedge-shaped protrusions tops. The granule introduction into the surface occurs in the force slip mode under the treating medium mass pressure $P_{m}$, which makes a relative movement at the speed of $v_{m}$.

When interacting with the surface being treated, the pellet wedge leaves micro-scratches on it with the parameters shown in Figure 2, where ho, $l_{s c}$ and $b$ denote the trace depth, length and width, respectively[15, 16].

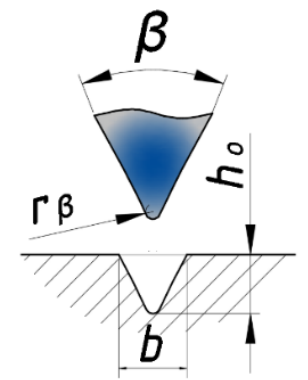

Fig. 2. Geometric diagram of wedge-shaped protrusion insertion into the part surface. 
The granule wedge insertion depth is defined as

$$
\mathrm{h}_{\mathrm{o}}=\frac{\mathrm{P}_{\mathrm{m}} \sqrt{1-\mathrm{f}^{2}}}{\pi \mathrm{r}_{\beta} \sigma_{\mathrm{s}}}
$$

where $P_{m}$ denotes the pressure at the contact point of the pellet top with the surface; $f$ is sliding friction ratio; $r_{\beta}$ is the radius at the vertex of the granule wedge; $\sigma_{\mathrm{s}}$ denotes the part material yield strength; $c$ is the ratio taking into account the contact carrying capacity increase during the transition to plastic deformation.

The area of the triangular-shaped scratch formed on the part surface will be equal to

$$
\mathrm{S}_{\mathrm{L}}=0,5\left(\mathrm{~b}_{\mathrm{i}}+2 \mathrm{r}_{\beta}\right)\left(\mathrm{h}_{0}-\mathrm{r}_{\beta}\right)+0.5 \pi \mathrm{r}_{\beta}^{2}
$$

where $b_{i}$ denotes the scratch width.

The granular medium circulation average speed is calculated by means of the wellknown formula

$$
v_{\mathrm{cp}}=2 \pi \mathrm{k}_{\mathrm{v}} \mathrm{k}_{\mathrm{B}} \mathrm{Af}_{\mathrm{K}}
$$

where A denotes the working chamber vibration amplitude; f means the machine-tool working chamber vibration frequency; $\mathrm{k}_{v}$ is the speed loss coefficient in the process of the pellet removal from the working chamber wall; $\mathrm{k}_{\mathrm{B}}$ is the coefficient taking into account the granules speed change in the relative motion process.

The micro-scratch length depends on the processed part Dp and the granule Dgr given diameters, and can be determined through analogy with the round grinding process:

$$
1_{\mathrm{L}}=\sqrt{\frac{\mathrm{D}_{\mathrm{p}} \mathrm{D}_{\mathrm{gr}} \mathrm{h}_{\mathrm{o}}}{\mathrm{D}_{\mathrm{p}}+\mathrm{D}_{\mathrm{gr}}}} \cdot \frac{\mathrm{t}_{\mathrm{p}}^{\mathrm{n}}}{100 \%}
$$

The material processed plasticity is known to affect the cutting process significantly, hence there is a need to apply the correction chip formation ratio $\mathrm{k}_{\mathrm{c}}=\mathrm{V}_{\mathrm{M}} / \mathrm{V}_{\mathrm{S}}$, where $V_{M}$ is the removed material amount in the of micro - chips form, and $V_{s}$ is the theoretical scratch volume. Taking this coefficient into account, the removed metal volume (in the micro-chips form) will be equal to

$$
\mathrm{V}_{\mathrm{M}}=0,51_{\mathrm{s}} \mathrm{k}_{\mathrm{c}}\left[\mathrm{r}_{\beta}\left(\pi \mathrm{r}_{\beta}+4 \mathrm{~h}_{\mathrm{o}}\right)+4 \mathrm{~h}_{\mathrm{o}} \cot 0,5 \beta_{\mathrm{sr}}\left(\mathrm{h}_{\mathrm{o}}-\mathrm{r}_{\beta}\right)\right]
$$

where $\beta_{s r}$ is the wedge-shaped vertices average angle (which is determined experimentally basing on the granules macrogeometry analysis); equals

Metal removal in case of a single granule interaction with the surface being treated

$$
q=\rho_{d} V_{M}
$$

where $r_{d}$ is the part material density, and taking the above dependencies into account, the equation for determining it will look the following way:

$$
\mathrm{q}_{0}=0,51_{s} \mathrm{k}_{\mathrm{c}} \rho_{\mathrm{d}}\left[\mathrm{r}_{\beta}\left(\pi \mathrm{r}_{\beta}+4 \mathrm{~h}_{\mathrm{o}}\right)+4 \mathrm{~h}_{\mathrm{o}} \cot 0,5 \beta_{\mathrm{sr}}\left(\mathrm{h}_{\mathrm{o}}-\mathrm{r}_{\beta}\right)\right]
$$

The criterion for evaluating the treatment efficiency by organic origin media means will be considered as the technological effect provided by treating a single workpiece surface contact zone. The contact zone size will be assumed as equal to the granule packaging square area obtained by connecting the circles centers of the given granule diameters $\mathrm{D}_{\mathrm{gr}}$. 
Taking the area of the formed scratch into account, we will determine the possible number of granules interacting with the unit surface area of the part being treated as $\boldsymbol{\tau}=$ $\mathbf{D}_{\boldsymbol{g r}} / \mathbf{v}_{\mathrm{cp}}$ :

$$
\mathrm{N}=\frac{\mathrm{D}_{\mathrm{gr}}^{2}}{\mathrm{~S}_{\mathrm{s}} \mathrm{P}}
$$

where $\mathrm{P}$ denotes the probability of the event that the granule medium interaction will result in micro-cutting.

Then the single surface contact zone treatment duration to ensure the metal removal with a thickness of $h_{o}$ will be equal to

$$
\mathrm{T}=\frac{\mathrm{D}_{\mathrm{gr}}{ }^{2}}{\mathrm{~b}_{\mathrm{i}} \mathrm{v}_{\mathrm{sr}} \mathrm{P}}
$$

The proposed relationship can be taken as a basis for determining the burr removal duration of when performing VVT by organic origin working media[17].

The triangular burr removal in the cross section will be considered as metal removal process, which will result in the burr height $\mathrm{H}$ reduction by the value of $\Delta \mathrm{H}=\mathrm{H}-\mathrm{Ra} \mathrm{a}_{\text {init }}$, where $\mathrm{Ra}_{\text {init }}$ is the initial surface profile average arithmetic mean deviation. In its turn, the value of $\Delta \mathrm{H}$ can be represented as a set of metal layers with thickness of ho with a variable area, which value varying with the burr height (Fig. 3).

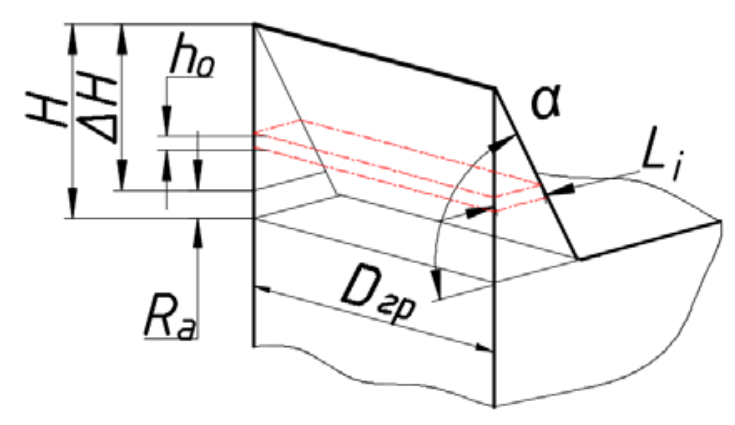

Fig. 3. Burr element model representation

As a result, we will get a dependence for burr removal duration determining

$$
\mathrm{T}_{3}=\frac{\mathrm{D}_{\mathrm{gr}} \mathrm{L}_{0}\left(\mathrm{H}-\mathrm{R}_{\text {init }}\right)}{2 \mathrm{~b}_{\mathrm{i}} \mathrm{v}_{\mathrm{sr}} \mathrm{Ph}_{\mathrm{o}}}
$$

where $\mathrm{L}_{\mathrm{o}}$ denotes the burr thickness at the base.

The main factors determining the treatment duration till deburring completion and ensuring the required parts surface quality and process efficiency are: the working medium granule size, and the machine-tool working chamber vibrations frequency. The dependences displayed in figure 4 prove that due to medium granulation and frequency increase, the processing time decreases in cases of all the sample materials studied. 

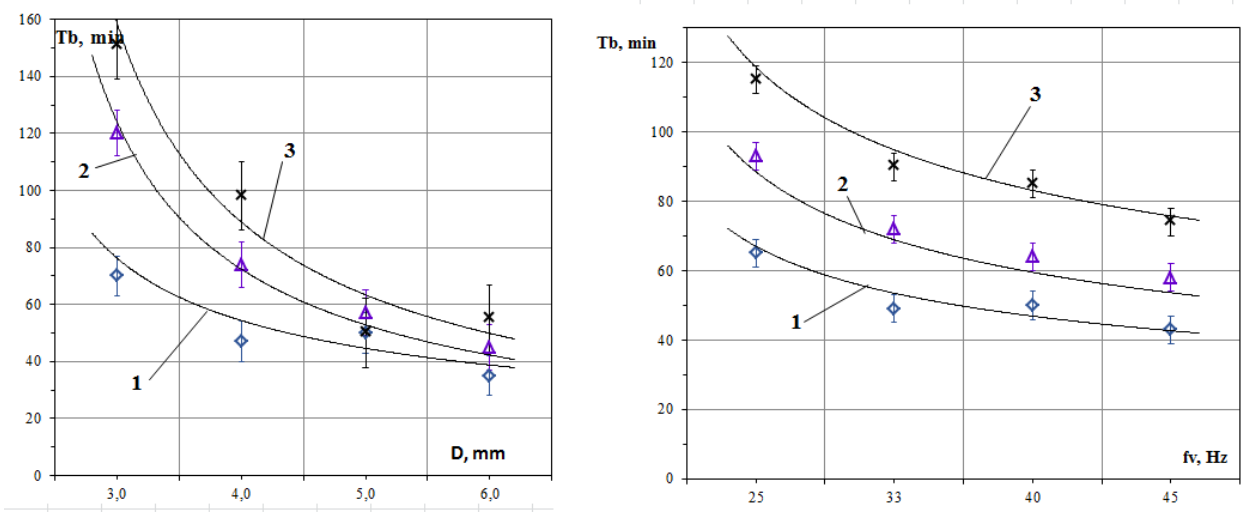

Fig. 4. Dependence of the burr T removal duration on the walnut shell granules size D (a) and on the machine-tool chamber vibrations frequency $f(b)$. Sample material: 1 - AMg6; 2 - LS-59-1; 3 BrOC4-3.

A research of burr removal duration effect depending on its location on the workpiece has also been made (Fig. 5).

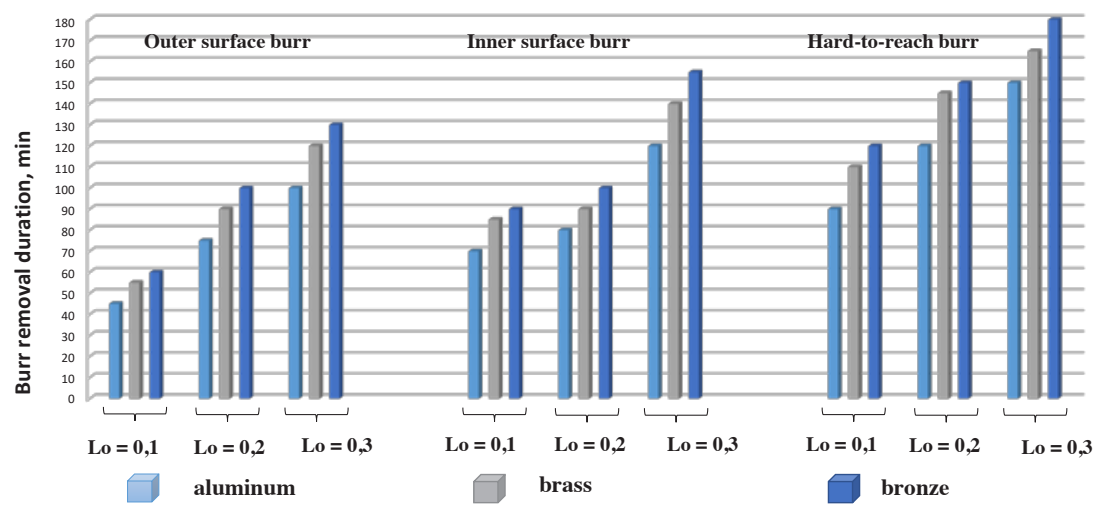

Fig. 5. Generalized diagrams of burr removal duration dependence basing on its location on the workpiece. Burr size Lo $=0.1 ; 0.2$ and $0.3 \mathrm{~mm}$.

\section{Conclusion}

Basing on the results of theoretical and experimental studies performed, the following conclusions can be made:

- the device parts finishing and cleaning treatment operation efficiency depends not only on the treated parts design and technological characteristics, but also on the shape, size and material of the treatment medium granules, which make a significant impact both on the quality of the treated surface and the VVT performance;

- the dependences obtained as a result of modeling for determining the VVT duration by bone processing media ensure the REE parts finishing and stripping operations efficiency and allow us to assess the main technological factors impact on the treatment process. 


\section{References}

1. Tamarkin, M.A., Smolentsev, E.V., Kolganova, Ye.N. Analiz sovremennogo sostojanija finishnykh metodov obrabotki v srede svobodnykh abrazivov i detalej, imejuschikh malyje pazy i otverstija (Small grooves and holes parts granular environment processing finishing methods present state analysis) // Vestnik Voronezhskogo gosudarstvennogo tekhnicheskogo universiteta (Voronezh State Technical University Bulletin) (2019). Vol. 15. № 1. Pp.122-129.

2. Kolganova, E.N., Goncharov V. M., Fedorov A. V. (2019). Investigation of deburring process at vibro-abrasive treatment of parts having small grooves and holes. Materials today: Proceedings, 19 (5), 2368-2373. doi.org/10.1016/j.matpr.2019.07.726.

3. Antonova, N.M. Evaluation of adhesion strength of protective coatings with $\mathrm{Al}$ powder by adhesion work of initial suspension towards metal surface. //MATEC Web of Conferences. - 2018. - Vol. 224: International Conference on Modern Trends in Manufacturing Technologies and Equipment (2018). - Article Number: 03011.

4. Antonova, N.M., Zinovyev, I.A., Khaustova, Ye.Yu., Boldyrev, F.M., Lisnitchenko, I.A. Opredeleniye adgezii putyom tsifrovoj obrabotki izobrazhenij poverkhnosti pokrytij (Adhesion determining by means of coating surface images digital treatment) // Inzhenernyj Vestnik Dona (Don Engineering Bulletin).(2019). № 1. URL: ivdon.ru/ru/magazine/archive/n1y2019/5549

5. Lebedev, V.A., Serga, G.V., Khandozhko, A.V. Increase of efficiency of finishingcleaning and hardening processing of details based on rotor-screw technological systems IOP Conf. Series: Materials Science and Engineering 327 (2018) 042062 doi:10.1088/1757-899X/327/4/042062.

6. Antonova, N.M., Shorkin, V.S., Romashin, S.N., Babichev, A.P. (2019). Adhesion of a Vibration Mechanochemical Solid-Lubricant $\operatorname{MoS}(2)$ Coating. Journal of Surface Investigation: X-ray, Synchrotron and Neutron Techniques, 13 (5), 848-854 doi: $10.1134 / \mathrm{S} 1027451019040025$

7. N.M. Antonova, A.P. Babichev, V.S. Berezovski. (2017). Study of the Morphology and Structure of Porous Composites Obtained from Na-CMC Suspensions with Aluminum Micro-Particles and Boehmite Nanoparticles. Journal of Surface Investigation: X-ray, Synchrotron and Neutron Techniques. - Vol. 11, No. 5. - P. 955959 doi: $10.1134 / \mathrm{S} 1027451017050032$

8. S.U. Shtyn, V.A. Lebedev, A.O. Gorlenko Thermodynamic aspects of the coating formation through mechanochemical synthesis in vibration technology systems IOP Conf. Series: Materials Science and Engineering 177 (2017) 012127 doi:10.1088/1757899X/177/1/012127.

9. V.V. Ivanov, N.S. Dontsov, A.V. Kirichek, Technological features of metallic zinc coatings obtained during mechanochemical synthesis, implemented in conditions of vibro-wave technological systems. (2018), IOP Conference Series: Materials Science and Engineering

10. V.V. Ivanov, A.P. Babichev, N.P. Pogorelov The research of technological characteristic of the vibrowave mechanical and chemical oxide coating formation. (2018), MATEC Web of Conferences

11. V.A. Lebedev, A A Kochubey and A V Kiricheck The use of the rotating electromagnetic field for hardening treatment of details /IOP Conf. Series: Materials Science and Engineering 177 (2017) 012126 doi:10.1088/1757-899X/177/1/012126. 
12. V.A. Lebedev, A.V. Kirichek., V.D. Sokolov Energy State of a Plastically Deformed Surface Layer / Procedia Engineering 150 (2016) 775 - 781, International Conference on Industrial Engineering, ICIE 2016.

13. I. A. Pinahin, V. A. Chernigovskii, A. A. Bratsikhin, M. A. Yagmurov, Kh. R. Sugarov Peculiar Properties of BK-8 Hard Alloy Wear after Volumetric Laser Pulsed Hardening under Production Conditions. Journal of Friction and Wear, (2017), Vol. 38, No. 2, pp. 86-91.

14. I. A. Pinakhin, V. A. Chernigovskii, A. A. Bratsikhin, M. A. Yagmurov, Kh. R. Sugarov Investigation into Physicomechanical Properties of VK6, VK8, and T5K10 Hard Alloys after Volumetric Pulsed Laser Hardening. Inorganic Materials, (2018), Vol. 54, No. 15, pp. 19-22.

15. Gillespie L K 1973 The formation and properties of machining burrs (Logan, Utah: Utah State University)

16. Ivanov V V, Popov S I and Kirichek A V (2017) Qualitative Characteristics of MoS2 SolidLubricant Coating Formed by Vibro-Wave Impact of Free-Moving Indenters J. Key Engineering Materials 736 18-22

17. Rouabhi Y, Lounis A and Babichev A P (2016) Improving the performance of vibratory treatment based on polymeric composite binder J. New Technol. Mater. 06 $38-43$ 